\title{
Isokinetic neck strength norms for schoolboy rugby forwards
}

\author{
D E du Toit (DPhil) \\ P Olivier (MA) \\ L Grenfell (MA) \\ B Eksteen (BA (Hons) Biokinetics)
}

Department of Human Movement Science, Nelson Mandela Metropolitan University, Port Elizabeth

\begin{abstract}
Objective. To generate isokinetic neck strength norms for schoolboy rugby forwards.

Design. Two hundred and eight schoolboys (17.21 - 1.03 years, mean - standard error of the mean (SEM), chosen from a population of under-19 first and second XV rugby players, participated in this study. The subjects were assessed anthropometrically and isokinetically according to a set protocol. The isokinetic assessment of neck strength was performed with the use of a specially designed stabilising chair and halo. The subjects performed a single maximal exertion set, consisting of 3 repetitions, through each of the cervical spinal movements in the sagittal and frontal planes. The data were analysed statistically according to positional categories (front-, second-, and back-row forwards), and were used to generate Stanine tables of normative data concerning the force characteristics of the cervical spine.
\end{abstract}

Results. The front-row forwards produced the largest amounts of force during the measurement of peak torque flexion (PTF $=30.00-1.39 \mathrm{Nm}$ ) and peak torque extension (PTE $=55.26-1.42 \mathrm{Nm}$ ). Conversely, the second-row forwards performed the best during the measurement of lateral flexion peak torque to the right $(\mathrm{PTR}=53.71-1.51$ $\mathrm{Nm})$ and lateral flexion peak torque to the left $(\mathrm{PTL}=52.92$ $-1.63 \mathrm{Nm}$ ) in the frontal plane. The front-row forwards were the most powerful in all the neck movements measured (power generated at 0.2 seconds during flexion $($ PowF $)=101.54-6.43 \mathrm{~W}$, power generated at $0.2 \mathrm{~s}$ during extension $($ PowE $)=167.31-8.03 \mathrm{~W}$, power generated

\section{CORRESPONDENCE:}

\section{P Olivier}

Department of Human Movement Science

Nelson Mandela Metropolitan University

PO Box 77000

Port Elizabeth

6031

Tel: 041 - 5042497

Fax: 041 - 5042770

E-mail: pierre.olivier@nmmu.ac.za at $0.2 \mathrm{~s}$ during lateral flexion to the right $($ PowR $)=211.92$ $-7.44 \mathrm{~W}$, and power generated at $0.2 \mathrm{~s}$ during lateral flexion to the left $($ PowL $)=194.81-7.73 \mathrm{~W})$. However, further analysis of the data revealed that few statistically significant differences $(p<0.01$ and $p<0.05)$ existed between the positional categories for the measured variables of peak torque, power generated at 0.2 of a second, peak torque to body mass ratio and cervical range of motion.

Conclusion. It appears that the various positional categories have not undergone the expected neck strength adaptations to meet the unique requirements of each position. The generation of neck strength normative data allows for the effective and quantified comparison of neck strength variables, enabling more effective injury prevention and rehabilitation.

\section{Introduction}

The incidence of cervical spinal injuries in rugby and other sporting and recreational activities has been well documented. ${ }^{1,3,5,15,18,19,21-23}$ Cervical spinal injuries that occur during organised team sports are well publicised; however, the majority of serious sports-related spinal injuries occur during unsupervised activities. ${ }^{18}$

The incidence of cervical spine injuries in rugby has brought about many precautionary measures including rule changes, new policies for selecting players, and conditioning principles. ${ }^{24}$ However, more players are exposed to potential injury situations due to the changing nature of the game. Previously the majority of cervical injuries occurred in the scrum, ruck or maul, involving mainly the forwards. ${ }^{19}$ Increasingly more cervical injuries now occur in the tackle situation, ${ }^{19}$ exposing the entire team to increased injury risk.

A mismatch of physical size and strength between players, combined with differences in skill levels creates a situation conducive to injuries. ${ }^{10}$ Research done in Argentine rugby showed that younger players aged between 15 and 21 years were at greater risk of muscle or ligament injuries of the cervical column, which could in turn cause more serious dislocations and/or spinal cord involvement. ${ }^{3}$

The following cervical spine injury requirements need to be met before the player can return to participation in collision 
sports; these include possessing normal strength, painless full range of motion, a stable vertebral column and adequate space for the neurological elements. ${ }^{17}$ While the external forces acting on the sportsman will not decrease, the player must find ways to withstand these forces in order to prevent injury. Proper conditioning of the neck musculature is a practical method of injury prevention. ${ }^{5-7,12,16,25}$ Through the course of any contact event the cervical spine is subjected to various forces, which have the potential to cause serious injury. Fortunately the spine is protected by the energy-absorbing capabilities of the paravertebral musculature and the intervertebral discs, which effectively dissipate these forces through controlled spinal motion. ${ }^{26}$ Neck strengthening can therefore improve the energy-absorption capabilities of the neck musculature, thus increasing protection of the cervical spine.

A comparison between neck muscle strength, efficiency and relaxation times in normal subjects and those with neck pain, found that all force values were significantly lower in those with neck pain. ${ }^{2}$ Several authors ${ }^{11,13,29}$ have demonstrated that the isometric strength measurement of neck muscles is an objective and practical method of estimating functional improvement in response to rehabilitation. In recent clinical studies ${ }^{9,11,20}$ intensive strength training of the neck muscles was used as the primary treatment for patients with chronic neck pain. The results of this intervention demonstrated reduced pain intensity and increased neck muscle strength

If cervical conditioning is to be used as an injury prevention and rehabilitation tool, then reliable data must be available to ascertain the condition of a players neck musculature and its ability to prevent injury. Normative data providing information on neck strength characteristics can assist in the identification, prevention, and ultimately the rehabilitation of individuals with poor neck musculature characteristics. Similar normative data collected from appropriate population groups (e.g. sedentary and other sporting codes) could be applied in the same fashion. The development of an isokinetic evaluation method assessing spinal movement in the frontal and sagittal planes, allows for reliable and valid measurement of neck strength parameters. ${ }^{6,7}$ It has been suggested in the literature that normative data on the strength of the neck musculature in healthy individuals are required for comparative evaluation of patients with neck pain. ${ }^{27}$ The meaningful application of these isokinetic test results therefore hinges on the availability of normative data from which comparisons and clinical conclusions can be drawn.

\section{Methodology}

\section{Subjects}

Two hundred and eight subjects with a mean age of 17.21 1.03 years were assessed anthropometrically and isokinetically to establish normative data values. The subjects were chosen from a population of under-19 first and second XV rugby players. Height and weight were measured prior to the subjects participation in the isokinetic assessment.

\section{Isokinetic cervical muscular strength testing}

Methods and procedures as proposed by du Toit ${ }^{6}$ and du Toit, et al. ${ }^{7}$ were used to examine the force capabilities of the schoolboy rugby forwards neck musculature. Torque production was measured through the full range of cervical spinal motion during flexion and extension in the sagittal plane and lateral flexion in the frontal plane (Fig. 1).

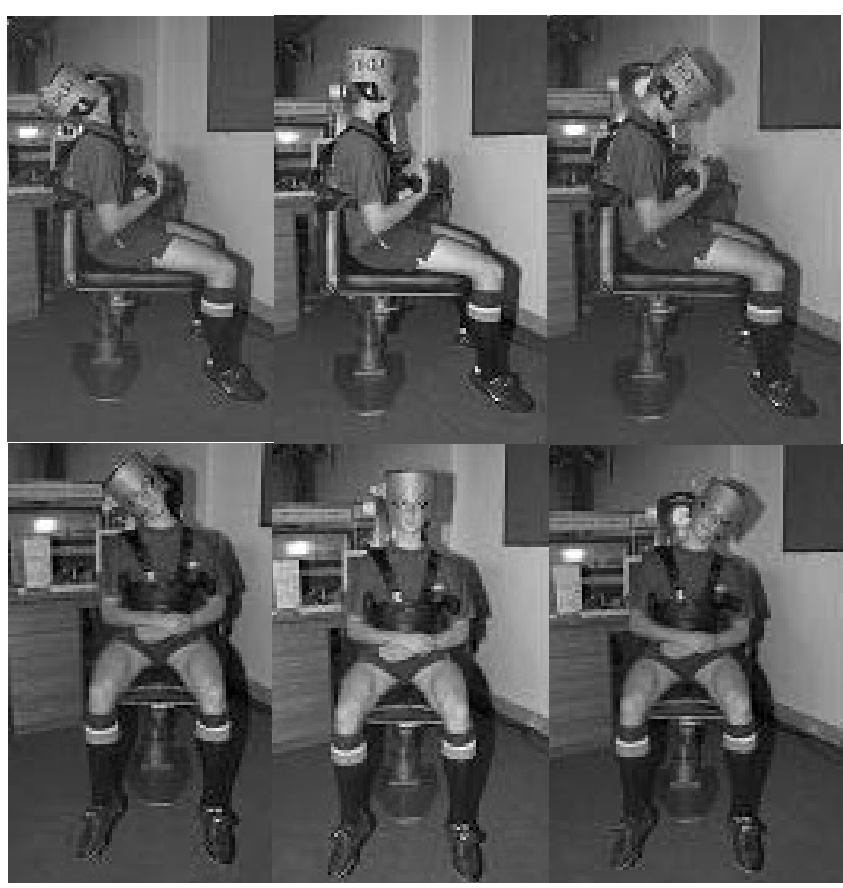

Fig. 1. Top: Movement pattern in the sagittal plane - extension to flexion. Bottom: Movement pattern in the frontal plane - lateral flexion to the right and left sides.

Prior to beginning the neck-strength evaluations, informed consent was obtained and participants answered a series of questions that screened for any prior or current cervical spinal injuries that may have precluded a subject from partaking in the study.

The evaluation session included a set series of warm-up exercises, viz. active full range of joint motion movements, static stretches, and submaximal isometric contractions. Six submaximal warm-up movements were then performed on the isokinetic dynamometer. After completing the 6 submaximal repetitions the subject $s$ head was placed in the neutral position and the range of motion of the dynamometer was reset to zero. When the subject was ready the isokinetic test commenced. Isokinetic strength testing was performed at $30 \ldots / \mathrm{s}$. Alignment of the dynamometer $s$ input axis corresponded with the vertebral prominence $(\mathrm{C} 7)$ of the cervical spine. Three repetitions of maximal effort through both flexion/extension and lateral flexion to the right and left were recorded and taken as being representative of the neck musculature s peak torque capabilities. ${ }^{6,7}$ 
Table I. Descriptive statistics of the schoolboy forwards' anthropometrical data according to positional categories $(N=208)$

\begin{tabular}{|c|c|c|c|c|c|c|c|c|c|}
\hline \multirow[b]{2}{*}{ Position } & \multirow[b]{2}{*}{$N$} & \multicolumn{2}{|c|}{ Height (cm) } & \multicolumn{2}{|c|}{ Weight (kg) } & \multicolumn{2}{|c|}{$\mathrm{NL}(\mathrm{cm})$} & \multicolumn{2}{|c|}{$\mathrm{NC}(\mathrm{cm})$} \\
\hline & & Mean & SEM & Mean & $\overline{\text { SEM }}$ & Mean & $\overline{\text { SEM }}$ & Mean & SEM \\
\hline Front row & 78 & $174.49^{*}$ & 0.64 & $85.62^{*}$ & 1.42 & $15.73^{*}$ & 0.19 & $39.98^{*}$ & 0.31 \\
\hline Second row & 52 & $184.30^{*}$ & 0.58 & 81.78 & 1.26 & $16.68^{*}$ & 0.23 & 38.93 & 0.25 \\
\hline Back row & 78 & $178.76^{*}$ & 0.66 & $76.61^{*}$ & 0.89 & 16.21 & 0.22 & $38.34^{*}$ & 0.20 \\
\hline Forwards & 208 & 178.54 & 0.45 & 81.28 & 0.75 & 16.45 & 0.13 & 39.09 & 0.16 \\
\hline \multicolumn{10}{|c|}{ * Statistically significant difference $(p<0.01)$} \\
\hline \multicolumn{10}{|c|}{ Statistically significant difference $(p<0.05)$} \\
\hline $\mathrm{NL}=$ neck le & neck & circumfere & , SEM & ard error & & & & & \\
\hline
\end{tabular}

\section{Cervical range of motion testing}

Two cervical range of motion (CROM) measurements were taken. The first measurement was taken during the subject $s$ performance of the 3 maximal cervical spinal motions. These CROM measurements were labelled maximal voluntary contraction range of motion flexion/extension (MVCRFE) and maximal voluntary contraction range of motion lateral flexion (MVCRLF) respectively. These measurements spanned the whole range of motion from full extension to full flexion and from full lateral flexion right to full lateral flexion left. Secondly, these measurements were broken down and represented as separate CROM measurements by taking into consideration the anatomical zero. These measurements were labelled maximal voluntary contraction range of motion extension (MVCRE), -flexion (MVCRF), -lateral flexion right (MVCRR), and -lateral flexion left (MVCRL).

\section{Statistical analysis}

The collected data were analysed and used to create normative data presented in Stanine tables. The Stanine tables consisted of 3 main categories; poor, average and good. Every main category also consisted of 3 subcategories. Stanine tables were generated for various measured and calculated variables, namely: peak torque (PT), power generated at 0.2 of a second (Pow), CROM, and PT ratios. Furthermore, one-way analysis of variance (ANOVA) was performed to detect any statistically significant differences for the measured and calculated variables between the various positional categories. Hypotheses were tested at the $99 \%$ and $95 \%$ confidence level. Statistical analyses, with the aid of the Pearson s moment product correlation coefficient, were also performed to investigate if certain variables were correlated.

\section{Results and discussion}

\section{Anthropometrical measurements}

The anthropometrical data are reflected in Table I according to the forward positional categories (front, second, and back row). The back-row forwards body mass proved to be significantly less than that of the front $(p<0.01)$ and second rows $(p<0.05)$. No significant difference existed between the body masses of the front and second-row forwards. The forwards body masses proved to be significantly positively correlated $(p<0.01)$ with their height and neck circumference (NC); however, it was not correlated to their neck length (NL).

Height was significantly positively correlated $(p<0.01)$ with body mass and NL, however no correlation existed between height and NC. As expected, the second row was significantly taller $(p<0.01)$ than the front and back rows. The relationship between height and NL may explain why the second row players had significantly longer necks $(p<0.01)$ than players in the front row.

\section{Isokinetic measurements}

\section{Peak torque}

No significant differences $(p>0.05)$ existed between the positional categories for the measurement of peak torque flexion (PTF), peak torque extension (PTE), peak lateral flexion torque to the right (PTR), or peak lateral flexion torque to the left (PTL) (Table II). This result, especially concerning the measurement of PTE, seems inconsistent with the function of the front row as well as the forces the front rows are exposed to in the scrum. Greater cervical extension strength was expected among the front-row forwards as this would be indicative of their adaptation to the demands of scrummag-

\begin{tabular}{|c|c|c|c|c|c|c|c|c|c|}
\hline \multirow[b]{3}{*}{ Position } & \multirow[b]{3}{*}{$N$} & \multicolumn{4}{|c|}{ Peak torque $(\mathrm{Nm})$} & \multicolumn{4}{|c|}{ Peak torque lateral flexion $(\mathrm{Nm})$} \\
\hline & & \multicolumn{2}{|c|}{ Flexion (PTF) } & \multicolumn{2}{|c|}{ Extension (PTE) } & \multicolumn{2}{|c|}{ Right (PTR) } & \multicolumn{2}{|c|}{ Left (PTL) } \\
\hline & & Mean & SEM & Mean & SEM & Mean & SEM & Mean & SEM \\
\hline Front row & 78 & 30.00 & 1.39 & 55.26 & 1.42 & 53.37 & 1.33 & 51.35 & 1.27 \\
\hline Second row & 52 & 26.04 & 1.24 & 54.69 & 1.57 & 53.71 & 1.51 & 52.92 & 1.63 \\
\hline Back row & 78 & 28.24 & 1.12 & 53.63 & 1.32 & 53.38 & 1.26 & 51.64 & 1.36 \\
\hline Forwards & 208 & 28.35 & 0.74 & 54.51 & 0.83 & 53.46 & 0.78 & 51.85 & 0.8 \\
\hline
\end{tabular}


Table III. Stanine table of normative data for peak torque $(N=208)$

\begin{tabular}{lllll}
\hline & \multicolumn{5}{c}{ Peak torque (Nm) } \\
\cline { 2 - 5 } $\begin{array}{l}\text { Extremes and } \\
\text { Stanine categories }\end{array}$ & Extension & Flexion & Right-flexion & Left-flexion \\
\hline Worst recorded & 28 & 9 & 24 & 14 \\
1. Extremely poor & $0-32$ & $0-12$ & $0-33$ & $0-28$ \\
2. Very poor & $33-39$ & $13-15$ & $34-41$ & $29-37$ \\
3. Poor & $40-44$ & $16-19$ & $42-45$ & $38-43$ \\
4. Below average & $45-50$ & $20-25$ & $46-49$ & $44-49$ \\
5. Average & $51-55$ & $26-29$ & $50-53$ & $50-52$ \\
6. Above average & $56-63$ & $30-34$ & $54-60$ & $53-59$ \\
7. Good & $64-70$ & $35-42$ & $61-66$ & $60-65$ \\
8. Very good & $71-77$ & $43-51$ & $67-72$ & $66-71$ \\
9. Excellent & $78+$ & $52+$ & $73+$ & $72+$ \\
Best recorded & 87 & 72 & 89 & 80
\end{tabular}

Table V. Stanine table of normative data for peak torque to body mass ratio $(N=208)$

\begin{tabular}{lllll}
\hline & \multicolumn{4}{c}{ Peak torque to body mass ratio (\%) } \\
\cline { 2 - 5 } $\begin{array}{l}\text { Extremes and } \\
\text { Stanine categories }\end{array}$ & Extension & Flexion & Right-flexion Left-flexion \\
Worst recorded & 32 & 12 & 28 & 20 \\
1. Extremely poor & $0-44$ & $0-17$ & $0-44$ & $0-38$ \\
2. Very poor & $45-50$ & $18-20$ & $45-49$ & $39-47$ \\
3. Poor & $51-56$ & $21-25$ & $50-56$ & $48-57$ \\
4. Below average & $57-62$ & $26-30$ & $57-60$ & $58-61$ \\
5. Average & $63-70$ & $31-36$ & $61-69$ & $62-66$ \\
6. Above average & $71-76$ & $37-41$ & $70-77$ & $67-74$ \\
7. Good & $77-87$ & $42-50$ & $78-84$ & $75-84$ \\
8. Very good & $88-92$ & $51-61$ & $85-91$ & $85-90$ \\
9. Excellent & $93+$ & $62+$ & $92+$ & $91+$ \\
Best recorded & 113 & 81 & 103 & 103 \\
& & & &
\end{tabular}

ing. As expected, PTF values were notably lower than those recorded for PTE; this was due to the relative size of the musculature involved in the force production during the recorded movements. Comparatively, PTR and PTL were very similar due to the bilateral muscular arrangement around the cervical spine.

The normative data generated from the collected PT measurements are presented in Stanine form in Table III. The maximum and minimum measurements taken for each PT variable by an individual are presented in the best and worst recorded rows. The three main Stanine categories, poor, average, and good, are further subdivided.

\section{Peak torque to body mass ratio}

Descriptive statistics for PT to body mass ratio (PT/BM) are given in Table IV. The back-row forwards had the greatest PT (PTF, PTE, PTR and PTL) to body mass ratios.

The back-row forwards proved to have a significantly higher $(p<0.05)$ PTF/BM than the second rows. Similarly, the back-row forwards proved to have a significantly higher $(p<$ $0.01)$ PTL/BM than the front rows. As no statistically significant differences existed between the positional categories on the measurements of PT (Table II), the significant differences observed for the PT/BM variables can be attributed to variations in body mass among the positional categories.

Table I shows that the second-row forwards were significantly heavier $(p<0.05)$ than the back rows. Thus the larger body masses of the second-row players resulted in a decreased and significantly lower $(p<0.05)$ PTF/BM than that of the back rows. Similarly, the front rows proved to be significantly heavier $(p<0.01)$ than the second-row players, resulting in the significantly lower $(p<0.01)$ PTL/BM average calculated. Thus the observed heavier body masses of the front-row players resulted in the significantly lower $(p<0.01)$ PTL/BM average calculated.

The normative data generated for the PT/BM variable is shown in Table V. As can be seen from this table PT/BM values for PTE, PTR, and PTL approach $100 \%$. The notable difference between the observed values of PTE/BM and PTF/BM is indicative of the variation in muscle mass and arrangement around the cervical spine and consequently the production of PT for the respective movement patterns. Likewise the similarity of the PTR/BM and PTL/BM results can also be attributed to the bilateral arrangement of the neck musculature involved in the respective cervical movement patterns.

\section{Power generated at $\mathbf{0 . 2}$ of a second}

Descriptive statistics (Table $\mathrm{VI}$ ) of the power generated at 0.2 of a second (Pow) variable, measured in Watts, revealed that the front-row forwards were best in all movement patterns. However, the numerical advantage translated into only 1 statistically significant difference. Front-row forwards proved to

Table IV. Descriptive statistics of the schoolboy forwards' peak torque to body mass data according to positional categories $(N=208)$

\begin{tabular}{|c|c|c|c|c|c|c|c|c|c|}
\hline \multirow[b]{2}{*}{ Position } & \multirow[b]{2}{*}{$N$} & \multicolumn{2}{|c|}{ PTF/BM } & \multicolumn{2}{|c|}{ PTE/BM } & \multicolumn{2}{|c|}{ PTR/BM } & \multicolumn{2}{|c|}{ PTL/BM } \\
\hline & & Mean & SEM & Mean & SEM & Mean & SEM & Mean & SEM \\
\hline Front row & 78 & 35.19 & 0.02 & 65.11 & 0.02 & 63.12 & 0.02 & 60.74 & 0.02 \\
\hline Second row & 52 & $31.62^{*}$ & 0.02 & 67.25 & 0.02 & 65.77 & 0.02 & 64.94 & 0.02 \\
\hline Back row & 78 & $37.09^{*}$ & 0.01 & 70.20 & 0.02 & 69.88 & 0.02 & 67.51 & 0.02 \\
\hline Forwards & 208 & 35.01 & 0.01 & 67.55 & 0.01 & 66.32 & 0.01 & 64.33 & 0.01 \\
\hline
\end{tabular}


Table VI. Descriptive statistics of the schoolboy forwards' power generated at $\mathbf{0 . 2}$ of a second data according to positional categories $(N=208)$

\begin{tabular}{|c|c|c|c|c|c|c|c|c|c|}
\hline \multirow[b]{3}{*}{ Position } & \multicolumn{9}{|c|}{ Power Generated at 0.2 of a second (W) } \\
\hline & \multirow[b]{2}{*}{$\mathbf{N}$} & \multicolumn{2}{|c|}{ PowF } & \multicolumn{2}{|c|}{ PowE } & \multicolumn{2}{|c|}{ PowR } & \multicolumn{2}{|c|}{ PowL } \\
\hline & & Mean & SEM & Mean & SEM & Mean & SEM & Mean & SEM \\
\hline Front row & 78 & $101.54^{*}$ & 6.43 & 167.31 & 8.03 & 211.92 & 7.44 & 194.81 & 7.73 \\
\hline Second row & 52 & 72.40 & 5.60 & 161.15 & 7.01 & 206.63 & 8.54 & 184.42 & 9.16 \\
\hline Back row & 78 & $69.17^{*}$ & 5.21 & 150.19 & 8.24 & 189.42 & 8.64 & 178.08 & 9.14 \\
\hline Forwards & 208 & 82.12 & 3.55 & 156.35 & 4.66 & 202.16 & 4.81 & 185.94 & 5.04 \\
\hline
\end{tabular}

Table VII. Stanine table of normative data for power generated at 0.2 of a second $(N=208)$

\begin{tabular}{|c|c|c|c|c|}
\hline \multirow{2}{*}{$\begin{array}{l}\text { Extremes and } \\
\text { Stanine } \\
\text { categories }\end{array}$} & \multicolumn{4}{|c|}{ Power generated at 0.2 of a second (watts) } \\
\hline & Extension & Flexion & Right-flexion & Left-flexion \\
\hline Worst recorded & 19 & 5 & 25 & 23 \\
\hline 1. Extremely poor & $0-25$ & $0-10$ & $0-70$ & $0-50$ \\
\hline 2. Very poor & $26-60$ & $11-20$ & $71-105$ & $51-80$ \\
\hline 3. Poor & $61-95$ & $21-40$ & $106-140$ & $81-120$ \\
\hline 4. Below average & $96-125$ & $41-55$ & $141-160$ & $121-160$ \\
\hline 5. Average & $126-160$ & $56-80$ & $161-220$ & $161-205$ \\
\hline 6. Above average & $161-205$ & $81-115$ & $221-250$ & $206-230$ \\
\hline 7. Good & $206-240$ & $116-150$ & $251-275$ & $231-260$ \\
\hline 8. Very good & $241-275$ & $151-210$ & $276-320$ & $261-310$ \\
\hline 9. Excellent & $276+$ & $211+$ & $321+$ & $311+$ \\
\hline Best recorded & 350 & 300 & 360 & 355 \\
\hline
\end{tabular}

be significantly more powerful $(p<0.01)$ than the back-row players on the measurement of flexion power generated at 0.2 of second (PowF). However, it was expected that the front-row players would be significantly stronger (Table II) and more powerful (Table VI) than the other positional categories. This would have been an indication of their adaptation to the demands of their position within the tight scrum.

The normative data for the power generated at 0.2 of a second variables are shown in Table VII. The data again show that the measurements made through the extension, lateral flexion right, and lateral flexion left movement patterns are fairly similar.

\section{Peak torque ratios}

The normative data represented in Table VIII show the muscle strength ratios of the agonist to antagonist for each specific movement pattern of the cervical spine assessed. As discussed previously, extension strength due to the muscle mass involved in the movement is much greater than that of flexion strength. This table illustrates that low ratios are rated as poor or below average $(0-39 \%)$. This is seen by the optimal ratio between PTF and PTE being approximately 49 $53 \%$. Normative data concerning the ratio of cervical flexion to extension strength in the normal population suggest that a ratio of around $60 \%$ is optimal. ${ }^{8}$ However among rugby forwards stronger cervical extensors are preferable as they will enable the player to resist the forces experienced in the tight

\begin{tabular}{|c|c|c|c|c|}
\hline \multirow{3}{*}{$\begin{array}{l}\text { Extremes and } \\
\text { Stanine } \\
\text { categories }\end{array}$} & \multicolumn{3}{|c|}{ Ratio (\% actual) } & \\
\hline & \multicolumn{2}{|c|}{ Flexion - Extension } & \multicolumn{2}{|c|}{ Right - Left } \\
\hline & Low & High & Low & High \\
\hline Worst recorded & 19 & 100 & 35 & 143 \\
\hline 1. Extremely poor & $0-11$ & $95+$ & $0-68$ & $132+$ \\
\hline 2. Very poor & $12-25$ & $81-94$ & $69-76$ & $124-131$ \\
\hline 3. Poor & $26-32$ & $74-80$ & $77-83$ & $117-123$ \\
\hline 4. Below average & $33-39$ & $67-73$ & $84-87$ & $113-116$ \\
\hline 5. Average & $40-43$ & $63-66$ & $88-92$ & $108-112$ \\
\hline 6. Above average & $44-48$ & $58-62$ & $93-95$ & $105-107$ \\
\hline 7. Good & $49-51$ & $55-57$ & $96-97$ & $103-104$ \\
\hline 8. Very good & $52-52$ & $54-54$ & $98-99$ & $101-102$ \\
\hline 9. Excellent & $53-53$ & $53-53$ & 100 & 100 \\
\hline Best recorded & 53 & 53 & 100 & 100 \\
\hline
\end{tabular}

scrum. Conversely, the bilateral symmetry of the musculature producing lateral flexion left and right predicts the optimal ratio for PTR to PTL to be $100 \%$.

These low ratios (Table VIII) can be attributed, in the case of PTF/PTE, to weak cervical flexors; conversely, too high a ratio (Table VIII) is also interpreted as poor or below average and indicative of weak cervical extensors. This principle is also applied in the reflection of PTR/PTL normative data.

\section{Cervical range of motion}

No statistically significant differences were observed between the positional categories during the measurement of CROM (Table IX). The average MVCRFE during the flexion movement pattern was $118.15 ß$. The mean values were $58.63 ß$ from full extension to neutral (anatomical zero) and $58.91 ß$ from neutral to full flexion. During the extension movement pattern a larger MVCRFE was measured (125.79ß). The mean values were $62.66 ß$ from full flexion to neutral and $64.12 ß$ from neutral to full extension. These values correspond well with other measurements reported in the literature. Buck et al. ${ }^{4}$ reported values of $66 ß-8 ß$ for flexion and $73 ß-9 ß$ for extension in a sample of young males. Lind et al. ${ }^{14}$ only reported a total average flexion and extension of $68 ß-26 ß$. Wolfenberger et al. ${ }^{28}$ established the mean CROM for flexion/extension, with the use of radiography, to be $108 \ldots$ in a sample $(N=39)$ of 20 - 29-year-old males. Dual inclinometry delivered a value of $101 \ldots$, and with a bubble 
Table IX. Descriptive statistics of the schoolboy forwards' cervical range of motion data according to positional categories $(N=208)$

\begin{tabular}{|c|c|c|c|c|c|c|c|c|c|}
\hline \multirow[b]{3}{*}{ Position } & \multicolumn{9}{|c|}{ Range of motion - MVCRFE \& MVCRLF (deg.) } \\
\hline & \multirow[b]{2}{*}{$N$} & \multicolumn{2}{|c|}{ Flexion } & \multicolumn{2}{|c|}{ Extension } & \multicolumn{2}{|c|}{ Right - flexion } & \multicolumn{2}{|c|}{ Left - flexion } \\
\hline & & Mean & SEM & Mean & SEM & Mean & SEM & Mean & SEM \\
\hline Front row & 78 & 117.19 & 1.8 & 123.29 & 1.74 & 109.54 & 1.43 & 109.46 & 1.38 \\
\hline Second row & 52 & 120.02 & 2.48 & 129.64 & 2.27 & 113.62 & 1.65 & 113.85 & 1.69 \\
\hline Back row & 78 & 117.86 & 1.99 & 126.04 & 1.85 & 112.71 & 1.29 & 111.68 & 1.33 \\
\hline Forwards & 208 & 118.15 & 1.18 & 125.76 & 1.11 & 111.75 & 0.84 & 111.39 & 0.84 \\
\hline
\end{tabular}

goniometer $100 \ldots$ of $\mathrm{CROM}$ for flexion/extension was obtained. ${ }^{28}$

Similar results were observed for the measurement of lateral flexion left and right CROM. However, the obtained results were smaller than those seen with the measurement of MVCRFE. The average MVCRLF to the left was 111.39ß, and during lateral flexion to the right an average of $111.75 ß$ was recorded. The mean values were $53.8 ß$ from neutral to

\begin{tabular}{|c|c|c|c|c|}
\hline \multirow{2}{*}{$\begin{array}{l}\text { Extremes and } \\
\text { Stanine } \\
\text { categories }\end{array}$} & \multicolumn{4}{|c|}{ Range of Motion - MVCRFE \& MVCRLF (deg) } \\
\hline & Extension & Flexion & Right-flexion & Left-flexion \\
\hline Worst recorded & 87 & 76 & 70 & 73 \\
\hline 1. Extremely poor & $0-96$ & $0-87$ & $0-86$ & $0-88$ \\
\hline 2. Very poor & $97-103$ & $88-97$ & $87-94$ & $89-94$ \\
\hline 3. Poor & $104-111$ & $98-104$ & $95-103$ & $95-102$ \\
\hline 4. Below average & $112-119$ & $105-114$ & $104-107$ & $103-108$ \\
\hline 5. Average & $120-131$ & $115-122$ & $108-114$ & $109-113$ \\
\hline 6. Above average & $132-138$ & $123-133$ & $115-121$ & $114-120$ \\
\hline 7. Good & $139-144$ & $134-141$ & $122-125$ & $121-125$ \\
\hline 8. Very good & $145-149$ & $142-145$ & $126-131$ & $126-132$ \\
\hline 9. Excellent & $150+$ & $146+$ & $132+$ & $133+$ \\
\hline Best recorded & 159 & 172 & 143 & 140 \\
\hline
\end{tabular}

Table XI. Stanine table of normative data for cervical range of motion $(N=208)$

\begin{tabular}{lcccc}
\hline $\begin{array}{l}\text { Extremes and } \\
\text { Stanine } \\
\text { categories }\end{array}$ & \multicolumn{5}{c}{$\begin{array}{c}\text { Range of motion - MVCRE, MVCRF, } \\
\text { MVCRR \& }\end{array}$} & MVCRL (deg) \\
\hline Extension & Flexion & Right-flexion Left-flexion \\
1. Extremely poor & $0-28$ & $0-26$ & $0-42$ & $0-32$ \\
2. Very poor & $29-43$ & $27-37$ & $43-47$ & $33-40$ \\
3. Poor & $44-50$ & $38-44$ & $48-50$ & $41-44$ \\
4. Below average & $51-57$ & $45-53$ & $51-55$ & $45-49$ \\
5. Average & $58-66$ & $54-62$ & $56-58$ & $50-55$ \\
6. Above average & $67-75$ & $63-70$ & $59-62$ & $56-58$ \\
7. Good & $76-80$ & $71-78$ & $63-67$ & $59-64$ \\
8. Very good & $81-87$ & $79-83$ & $68-71$ & $65-69$ \\
9. Excellent & $88+$ & $84+$ & $72+$ & $70+$ \\
Best recorded & 93 & 87 & 78 & 73 \\
& & & &
\end{tabular}

full lateral flexion right and $56.14 ß$ (average) from neutral to full lateral flexion to the left. Lind et al. ${ }^{14}$ reported slightly lower averages for both lateral flexion left and right CROM with a value of $45 ß-14 ß$. Active CROM for lateral flexion left to right, measured with a goniometer, for a sample $(N=20)$ of males aged from 11 to 19 years was calculated to be 91.1ß.30

The normative data represented in Stanine format in Tables $\mathrm{X}$ and $\mathrm{XI}$ show complete CROM measurements through the full range of cervical motion in the sagittal (MVCRFE) and frontal (MVCRLF) planes. The results show that the various positional categories do not appear to have undergone the expected specific neck musculature adaptations to meet the unique requirements of each position. This may be due to the lack of education of players and coaches on the importance of proper neck musculature condition for safe participation in rugby. This naturally leads to little time and effort spent by coaches and players on specific conditioning of the neck muscles resulting in underdeveloped and weak neck muscles. Furthermore, in conjunction with poor or insufficient conditioning of the neck muscles, players of the age investigated in this study possibly have not yet been exposed to sufficient bouts of cervical spinal exertion in the tight scrum to have undergone the needed adaptations. This is, however, more reason to encourage neck musculature conditioning.

\section{Conclusion}

The generation of normative data pertaining to the force characteristics of the neck musculature can be usefully applied as an injury prevention and rehabilitative tool. By identifying weak musculature in players prior to participation possible injury can be avoided. The usefulness of this method of assessment is not only limited to the sporting individual; the general population can also benefit from neck musculature conditioning to prevent or rehabilitate the painful cervical spine.

\section{REFERENCES}

1. Armour KS, Clatworthy BJ, Bean AR, Wells JE, Clarke AM. Spinal injuries in New Zealand rugby and rugby league - a twenty year survey. N Z Med $J$ 1997; 110: 462-5.

2. Barton PM, Hayes KC. Neck flexor muscle strength, efficiency, and relaxation times in normal subjects and subjects with unilateral neck pain and headache. Arch Phys Med Rehabil 1996; 77: 680-7.

3. Bottini E, Poggi EJT, Luzuriaga F, Secin FP. Incidence and nature of the most common rugby injuries sustained in Argentina (1991 - 1997). $\mathrm{Br} \mathrm{J}$ Sports Med 2000; 34: 94-7. 
4. Buck CA Dameron FB, Dow MJ, Skowlund HV. Study of normal range of motion in the neck utilizing a bubble goniometer. Arch Phys Med Rehabil 1959; 40: 390-92.

5. Cantu RC. Head and spine injuries in youth sports. Clin Sports Med 1995; 14: $517-32$.

6. Du Toit DE. The kinetics of rugby scrumming and the neck s force capabilities as a cause of cervical spinal injuries. DPhil dissertation, University of Port Elizabeth, 1993

7. Du Toit DE, Buys FJ, Venter DJL, Olivier PE. Isokinetic evaluation of neck strength. South African Journal of Sports Medicine 2003; 15(3): 3-10.

8. Garces GL, Medina D, Milutinovic L, Garavote P, Guerado E. Normative database of isometric cervical strength in a healthy population. Med Sci Sports Exerc 2002; 34: 464-70.

9. Highland TR, Dreising TE, Vie LL, Russel GS. Changes of isometric strength and range of motion of the isolated cervical spine after eight weeks of clinical rehabilitation. Spine 1992; 17: 77-82.

10. Hoskins TW. Prevention of neck injuries playing rugby. Public Health 1987; 101: 351-6.

11. Jordan $A$, Bendix $T$, Nielsen $H$, Hansen $F R, H_{i}$ st D, Winkel $A$. Intensive training, physiotherapy, or manipulation for patients with chronic neck pain: a prospective, single-blinded, randomized clinical trial. Spine 1998; 23: $311-9$

12. Kew T, Noakes TD, Kettles AN, Goedeke RE, Newton DA, Scher AT. A retrospective study of spinal cord injury in Cape Province rugby players, 1963 - 1989. S Afr Med J 1991; 80: 127-33.

13. Leggert SH, Graves JE, Pollock ML, et al. Quantitative assessment and training of isometric cervical extension strength. Am J Sports Med 1991; 19: 653 - 59

14. Lind $B$, Sihlbom $H$, Nordwall $A$, Malchau $H$. Normal range of motion of the cervical spine. Arch Phys Med Rehabil 1989; 70: 692-5.

15. Maroon JC, Bailes JE. Athletes with cervical spine injury. Spine 1996; 21: 2294-99.

16. Milburn PD. Biomechanics of rugby union scrimmaging: Technical and safety issues. Sports Med 1993; 16: 168-76.

17. Morganti C. Recommendations for return to sports following cervical spine injuries. Sports Med 2003; 33: 563-73.

18. Proctor MR, Cantu RC. Head and neck injuries in young athletes. Clin Sports Med 2000; 19: 693 - 715.

19. Quarrie KL, Cantu RC, Chalmers DJ. Rugby union injuries to the cervical spine and spinal cord. Sports Med 2002; 32: 633-53.

20. Randl $¿ \vee A$, fl stergaard $M$, Manniche $C$, et al. Intensive dynamic training for females with chronic neck/shoulder pain. A randomized controlled trial. Clin Rehabil 1998; 12:200 -10.

21. Rotem TR, Lawson JS, Wilson SF, Engel S, Rutkowski SB, Aisbett CW. Severe cervical cord injuries related to rugby union and league football in New South Wales, 1984 - 1996. Med J Aust 1998; 168: 379-81.

22. Scher AT. Rugby injuries to the cervical spine and spinal cord - a 10-year review. Clin Sports Med 1998; 17: 165-206.

23. Secin FP, Poggi EJT, Luzuriaga F, Laffaye HA. Disabling injuries of the cervical spine in Argentine rugby over the last 20 years. Br J Sports Med 1999; 33: 33-6.

24. Silver JR. The impact of the 21 st century on rugby injuries. Spinal Cord 2002; 40: 552-9.

25. Torg JS. Epidemiology, biomechanics, and prevention of cervical spine trauma resulting from athletics and other recreational activities. Operative Techniques in Sports Medicine 1993; 1: 159-68.

26. Torg JS, Vegso JJ, O Neill MJ, Sennett B. The epidemiologic, pathologic, biomechanical, and cinematographic analysis of football-enduced cervical spine trauma. Am J Sports Med 1990; 18(1): 50-7.

27. Winkelstein BA, Myers BS. The biomechanics of cervical spine injury and implications for injury prevention. Med Sci Sports Exerc 1997; 29: Suppl. 7, S246-55.

28. Wolfenberger VA, Bui Q, Batenchuk GB. A comparison of methods of evaluating cervical range of motion. J Manipulative Physiol Ther 2002; 25: 154-60.

29. Ylinen J, Ruuska J. Clinical use of neck isometric strength measurement in rehabilitation. Arch Phys Med Rehabil 1994; 75: 465-9.

30. Youdas JW, Garrett TR, Suman VJ, Bogard CL, Hallman HO, Carey JR. Normal range of motion of the cervical spine: An initial goniometric study. Physical Therapy 1992; 72: 770-80. 